\title{
Long-term outcomes after near-infrared sentinel lymph node mapping in non-small cell lung cancer
}

\author{
Christopher S. Digesu, MD, ${ }^{\mathrm{a}}$ Krista J. Hachey, MD, MPH, ${ }^{\mathrm{b}}$ Denis M. Gilmore, MD, ${ }^{\mathrm{c}}$ \\ Onkar V. Khullar, MD, ${ }^{\mathrm{d}}$ Hisashi Tsukada, MD, PhD, ${ }^{\mathrm{a}}$ Brian Whang, MD, ${ }^{\mathrm{a}}$ Lucian R. Chirieac, MD, \\ Robert F. Padera, MD, PhD, ${ }^{\mathrm{e}}$ Michael T. Jaklitsch, $\mathrm{MD},{ }^{\mathrm{a}}$ and Yolonda L. Colson, $\mathrm{MD}, \mathrm{PhD}^{\mathrm{a}}$
}

\begin{abstract}
Objective: To report the first analysis of long-term outcomes using near-infrared (NIR) image-guided sentinel lymph node (SLN) mapping in non-small cell lung cancer (NSCLC).
\end{abstract}

Methods: Retrospective analysis of patients with NSCLC enrolled in 2 prospective phase 1 NIR-guided SLN mapping trials, including an indocyanine green (ICG) dose-escalation trial, was performed. All patients underwent NIR imaging for SLN identification followed by multistation mediastinal lymph node sampling (MLNS) and pathologic assessment. Disease-free (DFS) and overall survival (OS) were compared between patients with $\mathrm{NIR}^{+}$SLN (SLN group) and those without (non-SLN group).

Results: SLN detection, recurrence, DFS, and OS were assessed in 42 patients with NSCLC who underwent intraoperative peritumoral ICG injection, NIR imaging, and MLNS. NIR ${ }^{+}$SLNs were identified in 23 patients (SLN group), whereas SLNs were not identified in 19 patients enrolled before ICG dose and camera optimization (non-SLN group). Median follow-up was 44.5 months. Pathology from $\mathrm{NIR}^{+}$SLNs was concordant with overall nodal status in all 23 patients. Sixteen patients with SLN were deemed pN0 and no recurrences were, whereas 4 of $15 \mathrm{pN} 0$ non-SLN patients developed nodal or distant recurrent disease. Comparing SLN versus non-SLN pN0 patients, the probability of 5-year OS is $100 \%$ versus $70.0 \%(P=.062)$ and 5-year DFS is statistically significantly improved at $100 \%$ versus $66.1 \%(P=.036)$, respectively. Among the 11 $\mathrm{pN}+$ patients, 7 were in the SLN group, with $>40 \%$ showing metastases in the SLN alone.

Conclusions: Patients with pNO SLNs showed favorable disease-free and overall survival. This preliminary review of NIR SLN mapping in NSCLC suggests that pNO SLNs may better represent true N0 status. A larger clinical trial is planned to validate these findings. (J Thorac Cardiovasc Surg 2018;155:1280-91)

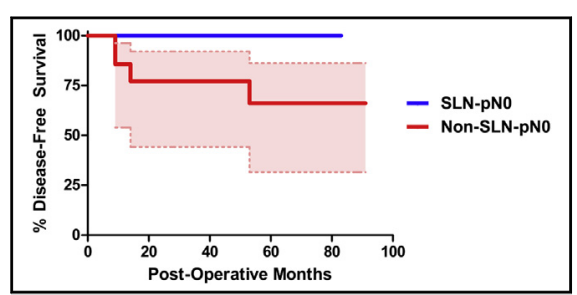

Improved disease-free survival in patients with pNO near-infrared sentinel lymph node.

\section{Central Message}

In non-small cell lung cancer, pathologically negative sentinel lymph nodes found by nearinfrared sentinel node mapping show favorable outcomes including overall and disease-free survival.

\section{Perspective}

Non-small cell lung cancer (NSCLC) prognosis is strongly linked to detection of metastatic regional lymph nodes (LN). Recurrence, despite negative nodes, suggests occult disease. Near-infrared image-guided sentinel lymph node (SLN) mapping offers an opportunity for targeted LN sampling and focused pathologic assessment. To date, long-term outcomes with SLN staging in NSCLC have not been reported.

See Editorial Commentary page 1292.
Lung cancer is the leading cause of cancer-related mortality in the United States, with more than 155,000 deaths expected in 2017. ${ }^{1}$ Despite early detection and surgical resection, nearly $30 \%$ of patients with early-stage lung cancer recur and 5-year survival remains between $60 \%$ and $80 \% .^{2-4}$ Prognosis is strongly linked to the detection of

\footnotetext{
From the ${ }^{\mathrm{a}}$ Division of Thoracic Surgery, and ${ }^{\mathrm{e}}$ Department of Pathology, Brigham and Women's Hospital, Boston, Mass; ' ter, Boston, Mass; ' Department of Thoracic Surgery, Vanderbilt University Medical Center, Nashville, Tenn; ${ }^{\mathrm{d} D}$ Division of Cardiothoracic Surgery, Emory University School of Medicine, Atlanta, Ga.

This work was supported by NIH R01CA131044, the Karl Storz Society of University Surgeons Resident Scholar Award (to K.H.), and the Brigham and Women's Hospital Advanced Training in Surgical Oncology T32 Fellowship (5T32CA009535) for K.H., C.D., D.G., and O.K.

Drs Digesu and Hachey contributed equally.
}

\footnotetext{
Read at the 97th Annual Meeting of The American Association for Thoracic Surgery, Boston, Massachusetts, April 29-May 3, 2017.

Received for publication April 10, 2017; revisions received Sept 1, 2017; accepted for publication Sept 16, 2017; available ahead of print Dec 14, 2017.

Address for reprints: Yolonda L. Colson, MD, PhD, Division of Thoracic Surgery, Department of Surgery, Brigham and Women's Hospital, 15 Francis St, Boston, MA 02115 (E-mail: ycolson@partners.org). $0022-5223 / \$ 36.00$

Copyright $(2017$ by The American Association for Thoracic Surgery https://doi.org/10.1016/j.jtcvs.2017.09.150
} 

Abbreviations and Acronyms
C-med = cervical mediastinoscopy
DFS = disease-free survival
EBUS = endobronchial ultrasonography
ICG = indocyanine green
$\mathrm{IQR}=$ interquartile range
LAD = lymphadenectomy
LVI = lymphovascular invasion
MLNS = mediastinal lymph node sampling
NIR $=$ near-infrared
NSCLC $=$ non-small cell lung cancer
OS $=$ overall survival
pNO = pathologic node negative
SLN = sentinel lymph node

Scanning this QR code will take you to the article title page. To view the AATS 2016 Webcast, see the URL next to the video thumbnail.

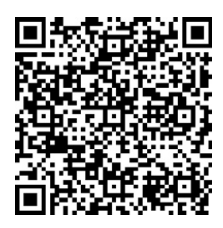

metastatic disease in local and regional nodes, and survival is reduced by even the presence of occult micrometastatic disease. ${ }^{5,6}$

Variability in lymphatic pathways and differences among surgeons in surgical lymph node staging remain critical barriers to accurate nodal staging in non-small cell lung cancer (NSCLC), resulting in understaging and the potential for residual occult nodal disease. ${ }^{7-9}$ Furthermore, extensive lymphadenectomy (LAD) may result in unnecessary mediastinal dissection in true pathologic node negative (pN0) cases as suggested by findings of the ACOSOG Z0030 randomized trial comparing mediastinal lymph node sampling (MLNS) with LAD in early-stage disease. ${ }^{10}$

The ability to systematically identify the first tumordraining lymph nodes (ie, sentinel lymph nodes [SLNs]) has the potential to improve the accuracy of staging in NSCLC by scrutinizing those nodes most likely to harbor occult metastatic disease. Focused assessment of the first tumor-draining lymph node(s) could identify a subset of patients harboring occult nodal disease who may benefit from an extensive LAD and/or adjuvant therapy. ${ }^{11}$ On further optimization of SLN mapping technology, true pNO patients may be spared a complete LAD because this potentially compromises subsequent nodal staging for a second primary lung cancer, a relatively common occurrence among patients with a previous early-stage lung cancer. ${ }^{12}$ Although SLN sampling has the potential to change the current standard of care, long-term outcomes from SLN staging in patients with NSCLC have not been reported.
Our group has previously reported the safety and feasibility of intraoperative minimally invasive near-infrared (NIR) SLN mapping in lung cancer. ${ }^{13,14}$ Using an optimized dose of NIR-detectable indocyanine green (ICG) dye, SLNs were identified in $100 \%$ of patients after transpleural peritumoral injection of ICG and in $80 \%$ of patients after transbronchial ICG injection. All patients also underwent subsequent MLNS, and SLN disease was concordant with the overall nodal status in all NSCLC cases.

Given that nodal disease was not identified in any other node within the subsequent MLNS specimen in patients with pathologically negative SLNs, we hypothesized that if negative SLNs represent true pN0 status, these patients would show improved disease-free survival (DFS) and overall survival (OS) without evidence of subsequent nodal recurrence. Thus, the aims of the current study are to evaluate the long-term incidence of recurrence and survival outcomes of patients enrolled in our ongoing phase 1 trials of NIR SLN mapping in patients with NSCLC.

\section{METHODS}

This study is a retrospective analysis of clinical outcomes from the prospective National Cancer Institute-funded NIR SLN mapping trial in NSCLC (ClinicalTrials.gov, NCT00264602) approved by the DanaFarber Cancer Institute Internal Review Board (Boston, Mass) as well as a pilot trial in navigational bronchoscopy-guided SLN mapping approved by the Partners Internal Review Board (Boston, Mass). Patient accrual began in February 2009 and is ongoing. Eligible patients included those with known or suspected NSCLC undergoing lung resection. The technique of transpleural or transbronchial peritumoral injection of ICG and NIR imaging was performed as previously described. ${ }^{13,14}$

All patients enrolled for NIR lymphatic mapping with known or suspected NSCLC were considered eligible for outcome analysis. One patient died during the immediate postoperative hospitalization of morbidity unrelated to the NIR study and was excluded from long-term outcome analysis. A patient with a suspected T4 lesion who received adjuvant chemotherapy and 2 patients with a Pancoast tumor and subsequently identified positive surgical margins were also excluded from analysis of recurrent disease given the high risk of local recurrence.

Initial patients were enrolled in a dose-escalation trial, and SLNs were not identified in the early patient cohort before ICG dose optimization. These patients underwent MLNS alone and served as the control group (non-SLN). With standardization of ICG dosing, SLNs were reliably identified, with these patients constituting the experimental SLN group.

Preoperative nodal staging was assessed via endobronchial ultrasonography (EBUS) and/or cervical mediastinoscopy (c-med) in patients based on clinical criteria. Importantly, all patients in this study had pathologic nodal staging via MLNS at the time of the lung resection as is standard of care, regardless of whether an SLN was identified. Routine microscopic evaluation of all nodes in the SLN and/or MLNS specimens was performed to evaluate for evidence of metastatic nodal disease in order to (1) assess whether SLN status is predictive of overall nodal status found via MLNS and (2) stratify patients as $\mathrm{pN} 0$ or $\mathrm{pN}^{+}$based on the absence or presence of metastatic nodal disease, respectively.

Duration of follow-up was defined as the interval between the date of surgery and the last patient contact. Disease recurrence was characterized as local (ipsilateral parenchymal recurrence), regional (nodal), distant (extrathoracic and/or contralateral metastatic disease), or a combination of these categories and was defined as either a biopsy-proven recurrence or 


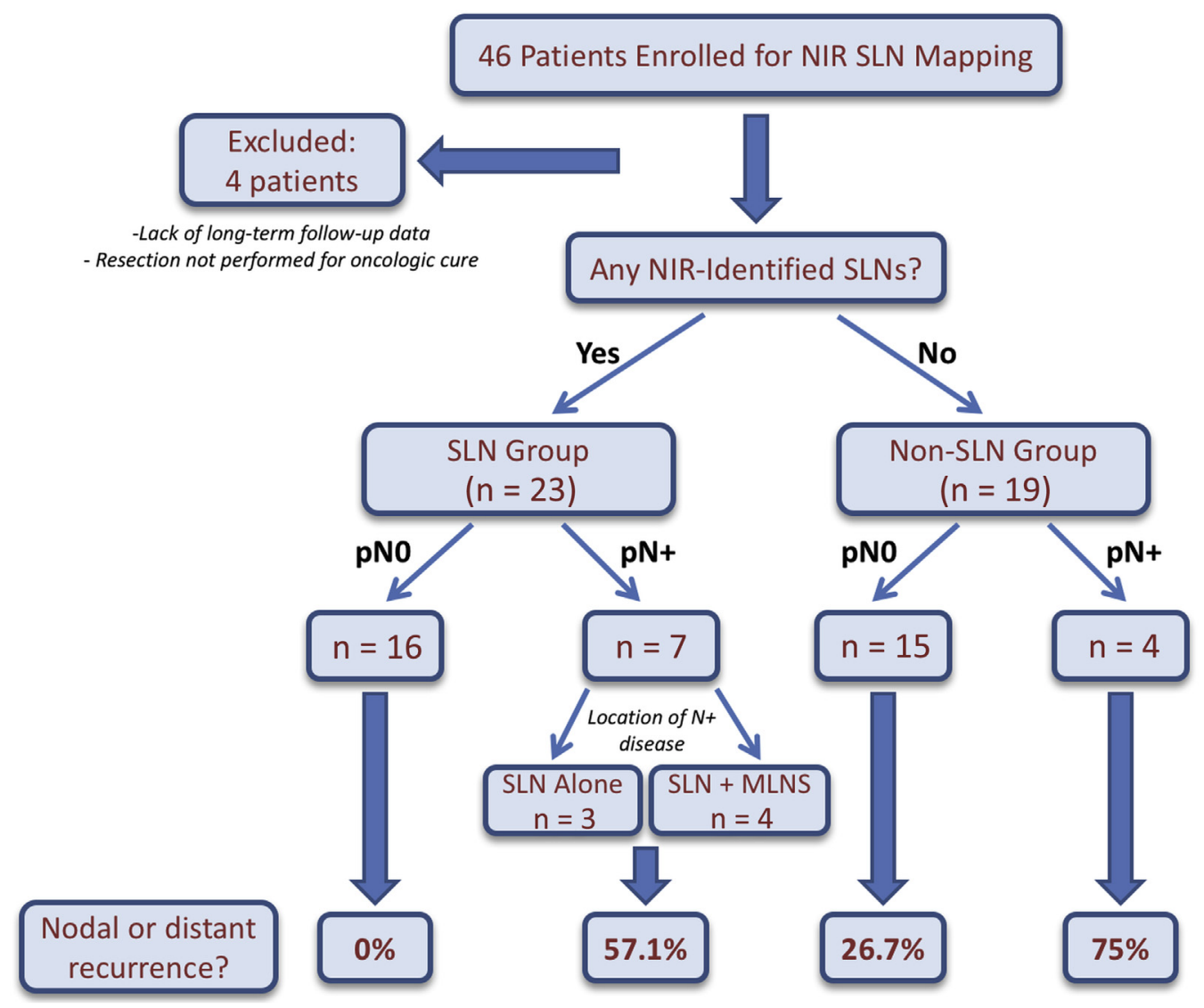

FIGURE 1. Study design and characteristics of sentinel lymph node $(S L N)$ and non-sentinel lymph node groups. NIR, Near-infrared; $M L N S$, mediastinal lymph node sampling.

imaging features highly suspicious for recurrence with clear radiologic and clinical documentation that resulted in a change in treatment plan.

A Mann-Whitney $U$ test was used for continuous data. A Fisher exact test and $\chi^{2}$ analysis were used for unordered categorical data, and a Jonckheere-Terpstra test was used for ordered categorical data. KaplanMeier survival analysis was performed to evaluate DFS and OS with logrank test for significance. For DFS analysis, patients were censored at the date last seen alive or at the date of death from other causes. GraphPad Prism 5.0 (La Jolla, Calif) or SAS (Cary, NC) were used for all analyses.

\section{RESULTS}

Forty-two patients undergoing peritumoral ICG injection, MLNS, and tumor resection, with or without SLN identification, were included for outcome analysis with a median follow-up of 44.5 months (interquartile range [IQR], 19-69 months). Patient groups and outcomes for each group are detailed in Figure 1. Initial patients enrolled were in a dose-escalation trial, and SLNs were not reliably identified before ICG dose optimization $(n=14)$ or in an additional 5 patients because of technical issues with ICG injection or the imaging system. These patients underwent MLNS alone and served as the non-SLN control group $(\mathrm{n}=19)$. With optimization of ICG dosing, at least 1 SLN was identified in 23 patients with 17 SLNs in the N1 station and 12 SLNs in the N2 station and a subsequent MLNS was performed. The detection of metastatic disease within the SLN in all $\mathrm{pN}^{+}$cases, and the absence of disease in the SLN when all other nodes were negative, yielded a

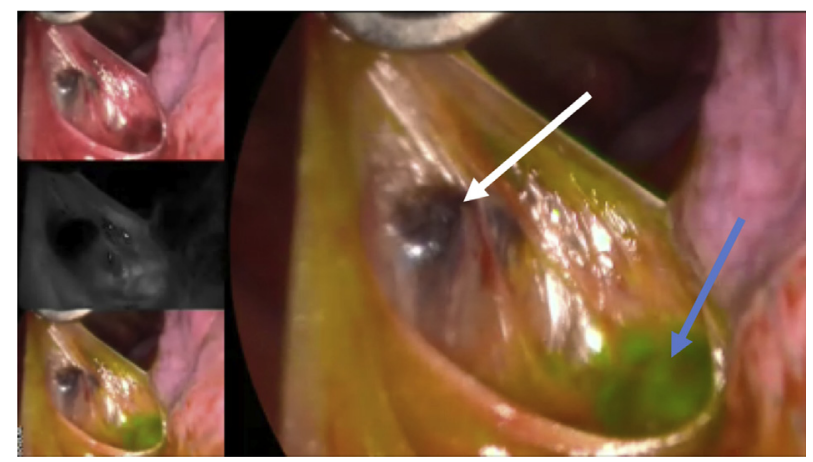

FIGURE 2. Level 7 lymph node following near-infrared sentinel lymph node mapping. The blue arrow indicates the sentinel lymph node that was the only lymph node positive for metastatic disease within this nodal station. The white arrow indicates another lymph node in the same station that was near-infrared-negative and did not show evidence of metastatic disease. 
TABLE 1. Demographic and pathologic characteristics of SLN and non-SLN cohorts

\begin{tabular}{|c|c|c|c|}
\hline Individual characteristics & $\begin{array}{l}\text { SLN group } \\
(\mathbf{n}=\mathbf{2 3})\end{array}$ & $\begin{array}{l}\text { Non-SLN group } \\
\quad(\mathbf{n}=19)\end{array}$ & $\begin{array}{c}P \\
\text { value } \\
\end{array}$ \\
\hline Mean age, y (SD) & $63(8.2)$ & $66(11.1)$ & .37 \\
\hline Female sex, n (\%) & $18(78.3)$ & $14(73.7)$ & 1.00 \\
\hline $\begin{array}{l}\text { Smoking status, } \mathrm{n}(\%) \\
\text { Never smoker } \\
\text { Current/former } \\
\geq 30 \text { pack-y } \\
\quad<30 \text { pack-y }\end{array}$ & $\begin{array}{r}2 \\
21(91.3) \\
13(61.9) \\
8(38.1)\end{array}$ & $\begin{aligned} & 1 \\
& 18(94.7) \\
& 10(55.5) \\
& 8(44.4)\end{aligned}$ & $\begin{array}{r}1.00 \\
.75\end{array}$ \\
\hline Mean ICG dose, mg (SD) & $1.73(1.0)$ & $0.85(1.06)$ & .01 \\
\hline $\begin{array}{l}\text { Method of ICG injection } \\
\text { Transpleural } \\
\text { Transbronchial }\end{array}$ & $\begin{array}{c}14 \\
9\end{array}$ & $\begin{array}{c}16 \\
3\end{array}$ & .17 \\
\hline $\begin{array}{l}\text { Extent of resection } \\
\text { Wedge } \\
\text { Segmentectomy } \\
\text { Lobectomy } \\
\text { Pneumonectomy }\end{array}$ & $\begin{aligned} 10 & (43.5) \\
3 & (13.0) \\
10 & (43.5) \\
0 & (0)\end{aligned}$ & $\begin{array}{l}6(31.6) \\
3(15.8) \\
9(62.5) \\
1(5.3)\end{array}$ & .64 \\
\hline $\begin{array}{l}\text { Histologic diagnosis, } \mathrm{n}(\%) \\
\text { Adenocarcinoma } \\
\text { Squamous cell carcinoma } \\
\text { Large cell with small cell foci }\end{array}$ & $\begin{aligned} 20 & (87.0) \\
2 & (8.7) \\
1 & (4.3)\end{aligned}$ & $\begin{array}{c}16(84.2) \\
3(15.8) \\
-\end{array}$ & .53 \\
\hline $\begin{array}{l}\text { Histologic grade* } \\
\text { Well differentiated } \\
\text { Moderately differentiated } \\
\text { Poorly differentiated }\end{array}$ & $\begin{array}{l}8(34.8) \\
9(39.1) \\
5(21.7)\end{array}$ & $\begin{array}{l}4(21.1) \\
8(42.1) \\
6(31.6)\end{array}$ & .38 \\
\hline Mean tumor size, $\mathrm{cm}(\mathrm{SD}) \dagger$ & $2.11(1.5)$ & $2.06(1.5)$ & .76 \\
\hline $\begin{array}{c}\text { Presence of LVI, n ( } \%) \\
\text { Among pN0 cases }\end{array}$ & $\begin{array}{l}5(21.7) \\
0(0)\end{array}$ & $\begin{array}{l}3(15.8) \\
2(13.3)\end{array}$ & $\begin{array}{l}.71 \\
.23\end{array}$ \\
\hline $\begin{array}{l}\text { Tumor mutation status, } \mathrm{n}(\%) \\
\text { EGFR } \\
\text { KRAS }\end{array}$ & $\begin{array}{l}1(4.3) \\
5(21.7)\end{array}$ & $\begin{array}{l}1(5.3) \\
2(10.5)\end{array}$ & $\begin{array}{r}1.00 \\
.43\end{array}$ \\
\hline $\begin{array}{l}P \text { values }<.05 \text { are shown in bold. } S L N, \\
I C G, \text { indocyanine green; } L V I, \text { lympho } \\
\text { tive; } E G F R, \text { epidermal growth factor re } \\
\text { gene. *One patient from SLN group wi } \\
\dagger \text { Based on final pathology. } \ddagger \text { For pNO ca } \\
\text { SLN group. }\end{array}$ & $\begin{array}{l}\text { cutinel lymp } \\
\text { cular invasi } \\
\text { ptor; } K R A S \text {, } \\
\text { out documer } \\
\mathrm{n}=16 \text { for }\end{array}$ & $\begin{array}{l}\text { de; } S D, \text { standar } \\
N O, \text { pathologic } \\
\text { ten rat sarcoma } \\
\text { on of tumor diff } \\
\text { group and } \mathrm{n}=\end{array}$ & $\begin{array}{l}\text { viation; } \\
\text { e nega- } \\
\text { l onco- } \\
\text { tiation. } \\
\text { or non- }\end{array}$ \\
\hline
\end{tabular}

sensitivity, specificity, positive predictive value, and negative predictive value for NIR-identified SLN mapping of $100 \%$.

The demographic and pathologic characteristics of the SLN and non-SLN groups are listed in Table 1. By definition, patients in the SLN group have a slightly shorter follow-up because they represent the subsequent cohort of patients after dose escalation of ICG. Patients were predominantly female $(76.2 \%)$ and current or former smokers $(92.9 \%)$, with primary lung adenocarcinoma $(85.7 \%)$ being the most common histologic diagnosis. The high incidence of sublobar resections in this retrospective analysis is secondary to the presence of pulmonary limitations, other clinical comorbidities, and/or radiographic characteristics that warranted a limited resection. There was preferential enrollment of patients with these characteristics for the localization trial detailed in Hachey et al. to show that this technology could be used to improve wedge resection and staging of lung lesions that are difficult to identify. ${ }^{14}$ There were no statistically significant differences in patient characteristics between the SLN and non-SLN groups, including extent of resection (sublobar vs lobar) or histologic subtype or grade, with the exception that the SLN group received a higher dose of ICG as expected during dose optimization.

\section{SLN Identify Metastatic Nodal Disease}

Among the 23 patients in whom at least 1 SLN was identified, 7 were found on final pathology to have nodal metastases. Metastases were detected in the NIR-identified SLN(s) in all 7 patients, even although analysis of other nodes within the MLNS specimen detected metastases in only 4 of these patients. Therefore, the SLN was the only node containing metastases in 3 patients despite having nodes sampled previously via c-med or from the same station via MLNS during surgery, as shown in Figure 2. Overall, occult metastatic disease was identified in $30 \%$ of the SLN specimens ( 7 of 23 patients), which was higher than the incidence of metastatic disease detected within the other MLNS-harvested nodes in both the SLN cohort (4 of 23 patients, $17.4 \%$ ) and the non-SLN cohort (4 of 19 patients, $21 \%)(P=1.00)$. The incidence of nodal disease detected within the MLNS of either group is similar to the $10 \%$ to $18 \%$ incidence of occult nodal disease commonly reported in the literature for clinical early-stage lung cancer but less than the $30 \%$ detected by SLNs in the current study. ${ }^{15,16}$

\section{Recurrence and Survival Outcomes in NSCLC $\mathbf{p N}^{+}$ (Node Positive) Patients}

Most node positive cases had N1 disease (73\%), with the SLN group containing 5 patients with N1 disease alone, 1 with both $\mathrm{N} 1$ and $\mathrm{N} 2$ disease, and 1 with $\mathrm{N} 2$ disease alone after examination of the SLN and MLNS specimens. Of the non-SLN patients, 3 had N1 disease and 1 patient had N2 disease within the MLNS specimen. All patients with nodal metastasis received appropriate adjuvant chemotherapy or chemoradiotherapy. Details regarding recurrence and survival outcomes for patients with positive nodes are outlined in Table 2.

Seven of 8 patients with lymphovascular invasion positive $\left(\mathrm{LVI}^{+}\right)$tumors in this study developed recurrent disease. Although there was no difference in incidence of $\mathrm{LVI}^{+}$tumors between the groups, metastatic nodal disease was detected within the SLN in all $\mathrm{LVI}^{+}$patients in the SLN group. This finding is in contrast to the non-SLN group, in which only $60 \%$ of patients with $\mathrm{LVI}^{+}$tumors were initially staged as $\mathrm{pN}^{+}$. All $\mathrm{LVI}^{+}$patients in the non-SLN group, including the $40 \%$ deemed $\mathrm{pN}$, 
TABLE 2. Recurrence and survival in pathologic node positive patients staged with sentinel lymph node (SLN) + mediastinal lymph node sampling (SLN group) versus mediastinal lymph node sampling alone (non-SLN group)

\begin{tabular}{|c|c|c|c|}
\hline $\mathbf{p N}^{+}$cohort characteristics & SLN group $(n=7)$ & Non-SLN group $(n=4)$ & $P$ value \\
\hline Number of LNs sampled, mean (SD)* & $10.67(6.6)$ & $15(11.05)$ & .45 \\
\hline Number of LN stations, mean (SD) & $3.67(1.75)$ & $5.75(2.22)$ & .14 \\
\hline $\begin{array}{l}\text { Pathologic N stage, n (\%) } \\
\quad 1 \\
2\end{array}$ & $\begin{array}{l}6(85.7) \\
1(14.3)\end{array}$ & $\begin{array}{l}3(75.0) \\
1(25.0)\end{array}$ & 1.0 \\
\hline Adjuvant chemo/chemoradiation, $\mathrm{n}(\%)$ & $7(100.0)$ & $4(100.0)$ & 1.0 \\
\hline Duration of follow-up from surgery, median, months (range) & $44(10-58)$ & $76.5(21-93)$ & .11 \\
\hline Lobectomy, n (\%) $†$ & $4(57.1)$ & $4(100.0)$ & .24 \\
\hline Adenocarcinoma, n (\%) & $7(100.0)$ & $2(50.0)$ & .11 \\
\hline Poorly differentiated, $\mathrm{n}(\%)$ & $3(42.9)$ & $0(0)$ & .24 \\
\hline Recurrence, $\mathrm{n}(\%) \ddagger$ & $4(57.1)$ & $3(75.0)$ & 1.00 \\
\hline Time to recurrence, median (range) & $10(4-46)$ & $17(9-40)$ & .63 \\
\hline Lung cancer-specific mortality, n (\%) & $3(42.9)$ & $2(50.0)$ & 1.00 \\
\hline \multicolumn{4}{|l|}{ 3-y outcomes $\S$} \\
\hline Overall survival, $(\%)$ & 71.4 & 75.0 & .31 \\
\hline Disease-free survival, $(\%)$ & 57.1 & 50.0 & .53 \\
\hline
\end{tabular}

$S L N$, Sentinel lymph node; $L N$, lymph node; $S D$, standard deviation. *Values include nodes sampled via cervical mediastinoscopy, endobronchial ultrasonography, sentinel lymph node, and other lymph nodes removed during surgery. Pathology reports that did not include the total number of nodes per station were defaulted to a single node, likely leading to underreporting of the nodes sampled. †Lobectomy (including pneumonectomy) versus sublobar resection. †़Time in months to initial diagnosis of nodal or distant recurrence. $\S$ Based on Kaplan-Meier analysis. Groups were compared in terms of time to event using log-rank test. For disease-free survival analysis, events included nodal or distant recurrences and disease-specific death.

recurred, suggesting that occult nodal disease was present but missed on routine histologic analysis of the MLNS specimen. The only $\mathrm{LVI}^{+}$patient without evidence of recurrent disease is a patient with SLN in which metastatic disease was detected within the SLN alone and who subsequently received adjuvant therapy early in her postoperative course.

There is no significant difference in recurrence rates or survival among $\mathrm{pN}^{+}$patients in the SLN or non-SLN groups, confirming that outcomes in patients with nodal

TABLE 3. Recurrence and survival in pathologic node negative patients staged with sentinel lymph node (SLN) + mediastinal lymph node sampling (SLN group) versus mediastinal lymph node sampling alone (non-SLN group)

\begin{tabular}{|c|c|c|c|}
\hline pNO cohort characteristics & SLN, pNO $(n=16)$ & Non-SLN, pNO $(n=15)$ & $P$ value \\
\hline Number of LNs sampled, mean (SD)* & $5(3.0)$ & $6(3.5)$ & .40 \\
\hline Number of LN stations sampled, mean (SD) & $3(1.7)$ & $4(1.5)$ & .21 \\
\hline Duration of follow-up from surgery, median, in months (range) & $25.5(9-83)$ & $47(12-91)$ & .29 \\
\hline Lobectomy, n (\%)† & $6(37.5)$ & $6(40.0)$ & 1.00 \\
\hline Adenocarcinoma, n (\%) & $13(81.3)$ & $14(93.3)$ & .60 \\
\hline Poorly differentiated, n (\%) & $2(12.5)$ & $6(40)$ & .22 \\
\hline Recurrence, $\mathrm{n}(\%) \ddagger$ & $0(0)$ & $4(26.7)$ & .04 \\
\hline Time to recurrence, median (range) & NA & $11.5(9-27)$ & NA \\
\hline Lung cancer-specific mortality, n (\%) & $0(0)$ & $2(13.3)$ & .23 \\
\hline \multicolumn{4}{|l|}{ 5-y outcomes $\S$} \\
\hline Overall survival, $(\%)$ & 100.0 & 70.0 & .062 \\
\hline Disease-free survival, $(\%)$ & 100.0 & 66.1 & .036 \\
\hline
\end{tabular}

$P$ values $<.05$ are in bold. $S L N$, Sentinel lymph node; $p N O$, pathologic node negative; $L N$, lymph node; $S D$, standard deviation; $N A$, not applicable. *Values include nodes sampled via cervical mediastinoscopy, endobronchial ultrasonography, sentinel lymph node, and other lymph nodes removed during surgery. Pathology reports that did not include the total number of nodes per station were defaulted to a single node, likely leading to underreporting of the nodes sampled. †Lobectomy versus sublobar resection. $\ddagger$ Time in months to initial diagnosis of nodal or distant recurrence. §Based on Kaplan-Meier analysis. Groups were compared in terms of time to event using log-rank test. For disease-free survival analysis, events included nodal or distant recurrences and disease-specific death. 
TABLE 4. Incidence of recurrence among pathologic node negative cases by presence or absence of sentinel lymph node identification

\begin{tabular}{|c|c|c|}
\hline \multirow[b]{2}{*}{ Recurrence type } & \multicolumn{2}{|r|}{ Recurrence description } \\
\hline & SLN group, $p N 0(n=16)$ & Non-SLN group, pN0 $(\mathrm{n}=15)$ \\
\hline Regional & $\begin{array}{l}\mathrm{n}=0 \\
\text { There were no cases of regional } \\
\quad \text { recurrence }\end{array}$ & $\begin{array}{l}\mathrm{n}=2 \\
\mathrm{R} 1: \text { T1aN0, moderately to poorly differentiated adenocarcinoma, } \mathrm{LVI}^{+} \\
\text {pN0 on c-med and MLNS specimens } \\
\text { RML lobectomy } \\
\text { Perihilar recurrence at } 53 \text { mo and subsequent vertebral metastases } \\
\text { Undergoing chemotherapy } \\
\text { R2: T1aN0, poorly differentiated squamous cell carcinoma } \\
\text { pN0 on MLNS specimens } \\
\text { LUL wedge resection } \\
\text { Treated intralobar recurrence but subsequently developed metastasis to } \\
\text { locoregional lymph nodes and chest wall } \\
\text { Undergoing chemotherapy }\end{array}$ \\
\hline Distant & $\begin{array}{l}\mathrm{n}=0 \\
\quad \text { There were no cases of distant } \\
\quad \text { metastasis }\end{array}$ & $\begin{array}{l}\mathrm{n}=2 \\
\mathrm{R} 3: \text { T2 bN0, poorly differentiated adenocarcinoma, } \mathrm{LVI}^{+} \\
\mathrm{pN} 0 \text { on c-med and MLNS specimens } \\
\text { RUL lobectomy } \\
\text { Distant parenchymal recurrence with multiple new PET avid nodules and brain } \\
\text { metastases at } 9 \text { mo } \\
\text { Died of metastatic disease at } 47 \text { mo postoperatively } \\
\text { R4: T2aN0, moderately differentiated adenocarcinoma, } \mathrm{KRAS}^{+}, \mathrm{VPI}^{+} \\
\text {pN0 on MLNS specimen } \\
\text { RUL wedge resection } \\
\text { Developed sternal and rib metastases at } 14 \text { mo } \\
\text { Undergoing chemotherapy }\end{array}$ \\
\hline
\end{tabular}

SLN, Sentinel lymph node; $p N O$, pathologic node negative; $R \#$, individual patient \# with a recurrence; $L V I$, lymphovascular invasion; $M L N S$, mediastinal lymph node sampling; $R M L$, right middle lobe; $L U L$, left upper lobe; $c-m e d$, cervical mediastinoscopy; $R U L$, right upper lobe; KRAS, Kirsten rat sarcoma viral oncogene; PET, positron emission tomography; VPI, visceral pleural invasion.

disease are related to the extent of nodal disease itself rather than whether disease is detected within the SLN or in other nodes within the MLNS specimen. Four of the $7 \mathrm{SLN} \mathrm{pN}^{+}$patients developed recurrent disease after adjuvant therapy (57\%), including 2 with distant only disease, 1 with regional and distant disease, and 1 with regional disease alone. In the non-SLN group, 3 of the 4 patients $(75 \%)$ recurred, with 1 patient having recurrence in the regional lymphatics and 2 patients developing distant metastases.

\section{Recurrence and Survival Outcomes for pNO Patients}

Although 4 patients with metastatic disease in the SLN also had metastatic disease in additional nodes, no patient with a pathologically negative SLN had evidence of nodal metastases in any other node within the MLNS specimen. Therefore, a pNO SLN correlated with the absence of metastatic disease (ie, pNO status) in the MLNS specimen. This finding leads to the hypothesis that patients with pNO SLN have more favorable longterm outcomes.

The recurrence rates and survival outcomes for $31 \mathrm{pN} 0$ patients (16 in the SLN group and 15 in the non-SLN control) are detailed in Table 3 . The overall median follow-up is
40 months (IQR, 14.5-69 months) with no significant difference in median follow-up between the SLN and non-SLN groups. No evidence of disease recurrence has been found in any patient in the pNO SLN group. In contrast, despite the nodes in the MLNS specimen being deemed pNO, 4 patients in the non-SLN group have developed nodal and/or distant recurrent disease. An additional patient who developed a local recurrence in the non-SLN group after a segmentectomy was not included because this recurrence was not related to nodal staging. This situation results in a $26.7 \%$ recurrence rate within the non-SLN patients versus $0 \%$ in the SLN group $(P=.04)$. The median time to recurrence was 11.5 months. Details of the regional and distant recurrences among non-SLN pN0 patients are summarized in Table 4.

This difference in recurrence does not appear to be secondary to differences in the cohort because there was no statistically significant difference between the SLN and nonSLN pNO cohorts in terms of the numbers of patients with lobar versus sublobar resections, adenocarcinoma, or tumor differentiation.

Kaplan-Meier curves of OS and DFS for pN0 patients in both the SLN and non-SLN groups are shown in Figure 3. For pN0 patients, the probability of OS at 5 years 


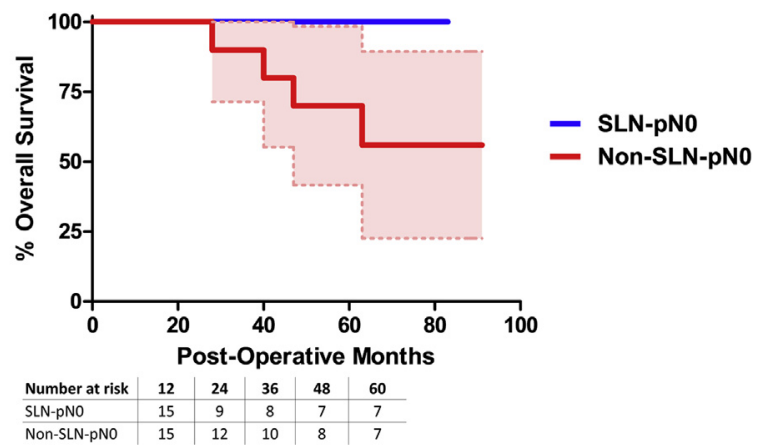

the non-SLN cohort was used as a control group for the subsequent cohort in which SLNs were identified. The groups were comparable given that all patients met the same enrollment criteria, received a peritumoral injection of ICG followed by NIR imaging for an SLN, and underwent standard MLNS and surgical resection of the tumor. Pathologic nodal status of both SLN and MLNS specimens was determined by a lung pathologist in a blinded fashion. There have been no nodal or distant recurrences or NSCLCrelated deaths in any patient with an identified SLN found negative for malignancy (pN0 SLN). In contrast, 4 of 15 pN0 patients in the non-SLN group developed nodal or distant recurrence despite the pN0 status of the MLNS specimen. This difference suggests that the SLN status is a better representation of the true overall nodal status. Furthermore, with a median follow-up of more than 3 years, the pNO SLN outcomes are better than those reported for early-stage NSCLC in previous studies., ${ }^{2,3}$

Although this is a small initial study, the difference in recurrence and DFS between the SLN and non-SLN groups is statistically significant and may be to the result of several factors. SLN mapping guides the surgeon to the first tumordraining lymph node(s) at greatest risk for metastatic disease. The ability to focus histologic analysis on tumor-specific SLNs, and thus identify true pN0 patients, may also at least partially explain the lower recurrence rates and better DFS noted in the pNO SLN group, particularly because standard assessment of MLNS nodes was performed in a blinded fashion for both the SLN and non-SLN patients. The better outcomes among the pNO SLN group do not seem to be secondary to bias within the cohorts because there was no statistically significant difference between the SLN and non-SLN pN0 cohorts in terms of number of patients undergoing lobar versus sublobar resections, pathologic diagnosis, tumor differentiation, or LVI. However, the higher rate of identification of occult $\mathrm{pN}^{+}$disease among patients with tumors of worse prognosis in the SLN versus non-SLN groups $(60 \%$ vs $0 \%$ in poorly differentiated tumors and $100 \%$ vs $33 \%$ in $\mathrm{LVI}^{+}$tumors) does suggest that the improved outcomes seen in the SLN pN0 cohort may result from shifting of previously deemed $\mathrm{pN} 0$ patients with undetected nodal disease into the correct $\mathrm{pN}^{+}$cohort.

SLN studies performed in other solid organs have shown the not-infrequent presence of more than 1 SLN (usually only 2). ${ }^{21}$ This situation has been shown to occur in the case of distally bifurcated lymphatic channels but also is likely to occur in the lung given the dual drainage patterns of the peribronchial and subpleural lymphatic pathways. We believe that the ability of NIR SLN mapping to identify SLNs within both N1 and N2 nodal stations as a function of individual patient differences in lymphatic drainage may reduce the potential for inadequate surgical nodal staging and missed occult disease as a result of surgeon variability in the aggressiveness and accuracy of nodal staging. ${ }^{9,22}$ 
SLN technology may identify occult nodal disease that might otherwise be missed, altering the treatment course by necessitating adjuvant chemotherapy. $\mathrm{LVI}^{+}$tumors have been associated with the development of early occult metastatic disease within lymph nodes and this correlates with our finding that of the $11 \mathrm{pN}^{+}$patients 6 had evidence of LVI on pathology. ${ }^{23}$ In the SLN group, metastatic disease was identified in the SLN in all 5 patients with $\mathrm{LVI}^{+}$tumors. This finding is in marked contrast to the non-SLN group in which 2 of the $3 \mathrm{LVI}^{+}$patients were deemed pN0 after standard histologic analysis of the MLNS specimen. Both of these patients subsequently developed metastatic nodal disease, suggesting that missed occult nodal disease in the MLNS specimen was responsible for the poorer outcomes in the non-SLN pN0 cohort. Although multiple previous studies have indicated worse outcomes associated with LVI, administering adjuvant chemotherapy based on LVI tumor status alone has not entered standard clinical practice. ${ }^{24}$ Therefore, the ability of SLN mapping to detect early isolated metastases in the SLN may offer a method of earlier detection and, consequently, early initiation of adjuvant treatment. The only patient alive and disease free with an $\mathrm{LVI}^{+}$tumor received early chemoradiation therapy for metastatic disease found only in the SLN, despite multiple nodes from the same level 7 station being negative in the MLNS specimen (Figure 2). Without targeted assessment of the SLN, adjuvant chemoradiation therapy would not have been initiated in the early postoperative period.

The mechanisms of lymphatic metastasis are not yet well understood, but the interplay between primary tumors and the SLN is increasingly recognized and merits further study. Early genomic and molecular changes in cancer cells promote evasion of apoptosis, downregulation of cell adhesion molecules, and crosstalk with immune cells in the tumor microenvironment, all of which serve to prime cells for motility and metastatic potential. ${ }^{25,26}$ Important for lymphatic metastasis, cancer cells and tumor-associated macrophages produce various growth factors that promote the development of new lymphatic vessels and the remodeling of existing channels, thereby increasing lymphatic flow to tumor-draining lymph nodes and creating a lymphatic niche for metastatic tumor cells. ${ }^{27}$ Once established within SLNs, cancer cells may continue to secrete growth factors that recruit lymphatic vessels beyond the SLN, resulting in distant organ dissemination, pointing to the significance of the sentinel lymph node.

The current study provides evidence that SLNs can be reliably identified in patients with NSCLC and presents an opportunity for focused study of the first population of tumor cells that metastasize from the primary tumor given the differential gene expression profiles and mutation status for key genes associated with carcinogenesis and metastasis. ${ }^{28-33}$ Genomic profiling of metastatic disease within SLNs has significant potential to identify specific mutations and biomarkers that can increase our understanding of early metastatic and primary tumor behavior in patients with lung cancer.

Although we achieved our goal of evaluating the longterm recurrence and survival of patients after the NIRmediated identification of SLNs, the current study is limited in its evaluation of overall outcomes and generalization to the NSCLC population as a whole given the small sample size, relatively short follow-up, high incidence of sublobar resections, and predominance of women and smokers within the cohorts. The current study is not a randomized study of SLN versus MLNS alone because all patients underwent MLNS or a formal LAD as per standard of care. Thus, we do not intend, nor do we have sufficient data, to propose that SLN mapping alone is equivalent to complete MLNS, particularly if nodal disease is present. However, our preliminary SLN data seem to support that definitive targeted SLN mapping may improve our ability over standard MLNS to identify patients who are truly pNO. If a pathologic negative SLN can be established to reflect a true overall pN0 status in subsequent prospective multicenter trials, additional aggressive LAD may not be necessary in future patients with small tumors, and selective SLN mapping would still allow targeted nodal staging if a patient were to subsequently develop a second primary tumor. In contrast, evidence of metastatic disease within the SLN is indicative of more advanced disease and advocates for a change to a neoadjuvant approach or a possible change in surgical resection with a subsequent radical LAD for both nodal staging and nodal clearance, depending on the nodes involved.

This is the first study to report long-term recurrence and survival outcomes in patients with NSCLC after NIRguided SLN mapping. We have identified favorable outcomes without evidence of nodal recurrence or distant metastasis in patients with pathologic negative SLNs, thus supporting our hypothesis that negative tumorassociated SLNs may be representative of the true overall nodal stage in patients with resectable NSCLC. Similarly, if metastatic nodal disease was detected in any nodes, it was always detected in the SLN, thus serving as an accurate marker for more advanced disease and necessitating an LAD to characterize the extent of metastatic disease. Larger, multicenter trials using NIR-guided SLN mapping in patients with early lung cancer are planned both to establish the reproducibility and accuracy of SLN mapping and to begin the necessary molecular and biochemical analysis on tumor-specific SLN to improve our understanding of the tumor-nodal relationship that sanctions early nodal metastasis. 


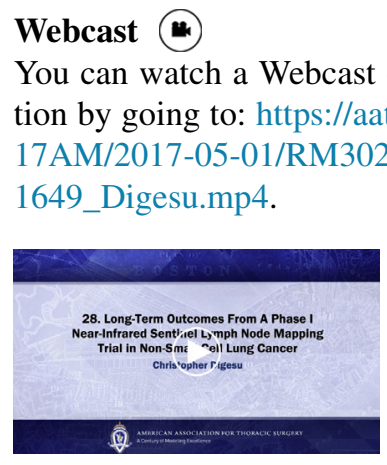

\section{Conflict of Interest Statement}

Authors have nothing to disclose with regard to commercial support.

We acknowledge Novadaq for the donation of ICG dye for the initial 10 patients undergoing navigational bronchoscopy localization as proof-of-concept. This work was conducted with support from Harvard Catalyst | The Harvard Clinical and Translational Science Center (National Center for Research Resources and the National Center for Advancing Translational Sciences, NIH Award UL1 TR001102) and financial contributions from Harvard University and its affiliated academic healthcare centers. The content is solely the responsibility of the authors and does not necessarily represent the official views of Harvard Catalyst, Harvard University and its affiliated academic healthcare centers, or the National Institutes of Health.

\section{References}

1. American Cancer Society. Cancer Facts \& Figures 2017. Atlanta, Ga: American Cancer Society; 2017.

2. Su S, Scott WJ, Allen MS, Darling GE, Decker PA, McKenna RJ, et al. Patterns of survival and recurrence after surgical treatment of early stage non-small cell lung carcinoma in the ACOSOG Z0030 (ALLIANCE) trial. J Thorac Cardiovasc Surg. 2014;2014:747-52.

3. Lee PC, Nasar A, Port JL, Paul S, Stiles B, Chiu YL, et al. Long-term survival after lobectomy for non-small cell lung cancer by video-assisted thoracic surgery versus thoracotomy. Ann Thorac Surg. 2013;96:951-60.

4. Varlotto JM, Recht A, Flickinger JC, Medford-Davis LN, Dyer AM, Decamp MM. Factors associated with local and distant recurrence and survival in patients with resected nonsmall cell lung cancer. Cancer. 2009;115:1059-69.

5. Martin LW, D'Cunha J, Wang X, Herzan D, Gu L, Abraham N, et al. Detection of occult micrometastases in patients with clinical stage I non-small-cell lung cancer: a prospective analysis of mature results of CALGB 9761 (Alliance). J Clin Oncol. 2016;34:1484-91.

6. He Z, Xia Y, Tang S, Chen Y, Chen L. Detection of occult tumor cells in regional lymph nodes is associated with poor survival in pN0 non-small cell lung cancer: a meta-analysis. J Thorac Dis. 2016;8:375-85.

7. Merritt RE, Hoang CD, Shrager JB. Lymph node evaluation achieved by open lobectomy compared with thoracoscopic lobectomy for N0 lung cancer. Ann Thorac Surg. 2013;96:1171-7.

8. Boffa DJ, Allen MS, Grab JD, Gaissert HA, Harpole HA, Wright CD. Data from the society of thoracic surgeons general thoracic surgery database: the surgical management of primary lung tumors. J Thorac Cardiovasc Surg. 2008;135: 247-54.

9. Little AG, Rush VW, Bonner JA, Gaspar LE, Green MR, Webb R, et al. Patterns of surgical care of lung cancer patients. Ann Thorac Surg. 2005;80:2051-6.

10. Darling GE, Allen MS, Decker PA, Ballman K, Malthaner RA, Inculet RI, et al, Randomized trial of mediastinal lymph node sampling versus complete lymph node sampling during pulmonary resection in the patient with N0 and N1 (less than hilar) non-small cell carcinoma: results of the American College of Surgery Oncology Group Z0030 Trial. J Thorac Cardiovasc Surg. 2011;141: $662-70$.

11. Hachey KJ, Colson YL. Current innovations in sentinel lymph node mapping for the staging and treatment of resectable lung cancer. Semin Thorac Cardiovasc Surg. 2014;26:201-9.

12. Boyle JM, Tandberg DJ, Chino JP, D'Amico TA, Ready NE, Kelsey CR. Smoking history predicts for increased risk of second primary lung cancer: a comprehensive analysis. Cancer. 2015;121:598-604.

13. Gilmore DM, Khullar OV, Jaklitsch MT, Chirieac LR, Frangioni JV, Colson YL. Identification of metastatic nodal disease in a phase 1 dose-escalation trial of intraoperative sentinel lymph node mapping in non-small cell lung cancer using near-infrared imaging. J Thorac Cardiovasc Surg. 2013;146:562-70.

14. Hachey KJ, Digesu CS, Armstrong KW, Gilmore DM, Khullar OV, Whang B, et al. A novel technique for tumor localization and targeted lymphatic mapping in early stage lung cancer. J Thorac Cardiovasc Surg. 2017;154:1110-8.

15. Licht PB, Jørgensen OD, Ladegaard L, Jakobsen E. A national study of nodal upstaging after thoracoscopic versus open lobectomy for clinical stage I lung cancer. Ann Thorac Surg. 2013;96:943-9.

16. Medbery RL, Gillespie TW, Liu Y, Nickleach DC, Lipscomb J, Sancheti MS, et al. Nodal upstaging is more common with thoracotomy than with VATS during lobectomy for early-stage lung cancer: an analysis from the national cancer data base. J Thorac Oncol. 2016;11:222-33.

17. Keating J, Newton A, Venegas O, Nims S, Zeh R, Predina J, et al. Near-infrared intra-operative molecular imaging can locate metastases to the lung. Ann Thorac Surg. 2017; 103:390-8.

18. Keating JJ, Runge JJ, Singhal S, Nims S, Venegas O, Durham AC, et al. Intraoperative near-infrared fluorescence imaging targeting folate receptors identifies lung cancer in a large-animal model. Cancer. 2017;123:1051-60.

19. Miyoshi S. Intraoperative nodal staging: role of sentinel node technology. Thorac Surg Clin. 2013;23:357-68.

20. Liptay MJ, D’Amico TA, Nwogu C, Demmy TL, Wang XF, Gu L, et al. Intraoperative sentinel node mapping with technitium-99 in lung cancer: results of CALGB 140203 multicenter phase II trial. J Thorac Oncol. 2009;4: 198-202.

21. Mamounas EP, Kuehn T, Rutgers EJT, von Minckwitz G. Current approach of the axilla in patients with early-stage breast cancer. Lancet. August 14, 2017 [Epub ahead of print].

22. Lardinois D, Suter H, Hakki H, Rousson V, Betticher D, Ris HB. Morbidity, survival and site of recurrence after mediastinal lymph-node dissection versus systematic sampling after complete resection for non-small cell lung cancer. Ann Thorac Surg. 2005;80:268-75.

23. Zhang Y, Sun Y, Xiang J, Zhang Y, Hu H, Chen H. A clinicopathologic prediction model for postoperative recurrence in stage Ia non-small cell lung cancer. $J$ Thorac Cardiovasc Surg. 2014;148:1193-9.

24. Mollberg NM, Bennette C, Howell E, Backhus L, Devine B, Ferguson MK. Lymphovascular invasion as a prognostic indicator in stage 1 non-small cell lung cancer: a systematic review and meta-analysis. Ann Thorac Surg. 2014; 97:965-71.

25. Perlikos F, Harrington KJ, Syrigos KN. Key molecular mechanisms in lung cancer invasion and metastasis: a comprehensive review. Critical Rev Oncol Hematol. 2013;87:1-11.

26. Eruslanov EB, Bhojnagarwala PS, Quatromoni JF, Stephen TL, Ranganathan A, Deshpande C, et al. Tumor-associated neutrophils stimulate $\mathrm{T}$ cell responses in early-stage human lung cancer. J Clin Invest. 2014;124:5466-80.

27. Chandrasekaran S, King MR. Microenvironment of tumor-draining lymph nodes: opportunities for liposome-based targeted therapy. Int J Mol Sci. 2014;15: 20209-39.

28. Hoang CD, Guillaume TJ, Engel SC, Tawfic SH, Kratzke RA, Maddaus MA. Analysis of paired primary lung and lymph node tumor cells: a model of metastatic potential by multiple genetic programs. Cancer Detect Prev. 2005;29: 509-17.

29. Bozzetti C, Tiseo M, Lagrasta C, Nizzoli R, Guazzi A, Leonardi F, et al. Comparison between epidermal growth factor receptor (EGFR) gene expression in primary non-small cell lung cancer (NSCLC) and in fine-needle aspirates from distant metastatic sites. J Thorac Oncol. 2008;3:18-22.

30. Monaco SE, Nikiforova MN, Cieply K, Teot LA, Khalbuss WE, Dacic S. A comparison of EGFR and KRAS status in primary lung carcinoma and matched metastases. Hum Pathol. 2010;41:94-102. 
31. Gomez-Roca C, Raynaud CM, Penault-Llorca F, Mercier O, Commo F, Morat L, et al. Differential expression of biomarkers in primary non-small cell lung cancer and metastatic sites. J Thorac Oncol. 2009;4:1212-20.

32. Kikuchi T, Daigo Y, Ishikawa N, Katagiri T, Tsunoda T, Yoshida S, et al. Expression profiles of metastatic brain tumor from lung adenocarcinomas on cDNA microarray. Int J Oncol. 2006;28:799-805.

33. Schmid K, Oehl N, Wrba F, Pirker R, Pirker C, Filipits M. EGFR/KRAS/BRAF mutations in primary lung adenocarcinomas and corresponding locoregional lymph node metastases. Clin Cancer Res. 2009;15:4554-60.

Key Words: sentinel lymph node, near-infrared, lung cancer, outcomes

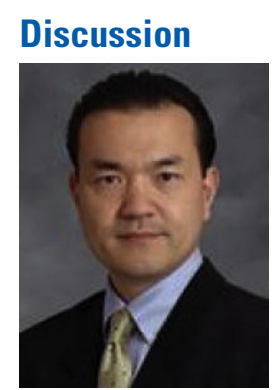

Dr Kazuhiro Yasufuku (Toronto, Ontario, Canada). Dr Digesu, I congratulate you for an excellent presentation. I do have a few disclosures myself related to this presentation. I have been involved in a single center clinic research trial using the Novadaq system, an ICG for tumor localization, and also I am a strong believer in your infrared imaging.

Intraoperative near-infrared imaging using ICG is a novel technology that has been introduced into the field of thoracic surgery. NRI has been used for sentinel lymph node mapping, tumor localization during minimally invasive lung resection, identification of segmental plane during segmentectomy, as well as assessment of the conduit during esophagectomy. Your group have been leaders in the field of sentinel lymph node mapping using this technology, and I really enjoyed reading your manuscript on the long-term outcomes of patients who underwent sentinel lymph node mapping. In your presentation you showed that patients with pathological N0 sentinel lymph nodes exhibited favorable disease-free and overall survival compared to control groups, although the numbers were very small.

I have several questions which I will ask one at a time. The first question is a technical question. In your study, injection of ICG was performed either transpleurally or transbronchial. What was the advantage or disadvantage of performing the injection through the transparenchymal versus the transbronchial and if you can tell us why you changed the approach.

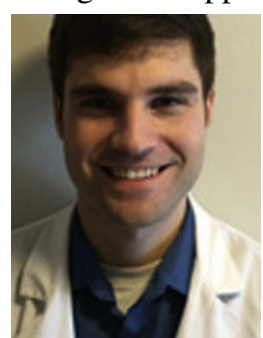

Dr Christopher S. Digesu (Boston, Mass). Thank you for the questions and the comments. We started using navigational bronchoscopy to inject the indocyanine green through the bronchus because it allowed us to avoid spillage during the operation and it also didn't require a palpable tumor during the operation and so we used that for early-stage cancers.
Dr Yasufuku. Do you see an advantage comparing the 2 methods? Have you noticed any difference?

Dr Digesu. It is definitely more difficult with the transpleural due to the spillage. You create a hole in the pleura when you inject and that creates background signal in the chest cavity. In our navigational bronchoscopy trial, we had greater than $80 \%$ sentinel lymph node yield.

Dr Yasufuku. Next question. Why did almost half of your patient population undergo a limited resection rather than a lobectomy? I believe about $50 \%$ of the patients either had a wedge or a segmental resection.

Dr Digesu. That's correct. There was no significant difference between the 2 groups if they had a complete resection or if they had a sublobar resection. For this particular study, we preferentially enrolled patients who had undergone a wedge resection specifically in the nav bronch trial, because we wanted to localize lesions as well as identify the sentinel nodes. So there was a higher incidence of wedge resections in that trial.

Dr Yasufuku. Next question. Based on your data, what do you think is the advantage for thoracic surgeons clinically doing surgeries performing sentinel lymph node mapping during surgery? How does it change management of our patients? We have heard many talks today and yesterday about nodal dissection. I believe most of us will be doing a lymph node dissection during the surgery. How will it change our practice?

Dr Digesu. I think it just guarantees that you get the correct node. You can do a dissection but if you miss one node as in the one particular patient that I presented, multiple nodes had been sampled in other stations and within that station, and the near-infrared identified node was the only one that was found to have metastatic disease. So had you not taken that one particular node, this patient would have been staged as a stage $I$ and not received chemoradiotherapy.

Dr Yasufuku. So you are saying that maybe we can be a bit more aggressive in terms of lymph node dissection. So the next question is, do you think there was a difference in the aggressiveness of the lymph node dissection between the 2 groups that you compared, because in the control group you were not able to see the sentinel lymph node. Do you think there was a difference?

Dr Digesu. I think so, but I think that is the advantage of the technology. If you see green dye traveling to a station, you are going to make sure that you get all of the nodes within that particular station.

Dr Yasufuku. One last question is, do you think the sentinel lymph node technology would give us more information in terms of deciding intraoperatively whether we can do a sublobar resection versus a lobectomy, for instance, a segment or a wedge versus a lobectomy? 
Dr Digesu. I do. I think that if you were to have a sentinel node that came back as positive, it may lead you to doing a more formal resection.

Dr Yasufuku. Thank you very much.

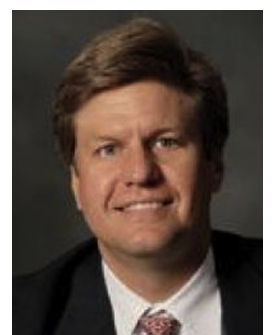

Dr Michael J. Liptay (Chicago, Ill). Thanks, that was a great presentation, and obviously you and Dr Colson are leaders in this field. It was super.

I have a question about what you did with the sentinel lymph node once you identified it pathologically. One of the things that we found a while back is that doing additional serial sectioning or immunohistochemistry could allow you to identify micrometastatic disease. Did you handle the sentinel lymph nodes that you identified differently pathologically?

Dr Digesu. In the first trial they did undergo staining for micrometastatic disease but in the second trial using nav bronch they didn't, so we have not included it in this study.

Dr Liptay. I see. I didn't want to beat a dead horse about the wedge resection, but as you are trying to understand the sentinel node mapping, I think one of the things is to understand the false sentinel lymph nodes where you may have dye going to a sentinel node and it is negative and another node may be positive, and so if you limit yourself on your dissection, you are going to miss that data.

Dr Digesu. At least in our studies of all the patients we have ever done, we have never had a negative sentinel node but another node that ended up being positive. They have always been correlated.

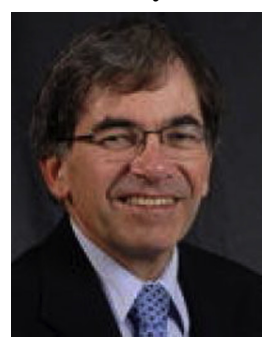

Dr Thomas M. Egan (Chapel Hill, $N C$ ). Very nice presentation. I had a couple of questions. One is, the location of the sentinel node, was it usually at the hilum of the lobe or was it usually segmental, or where was it?

Dr Digesu. Consistent with reported literature, we had about a $20 \%$ skip rate. In the first trial we did find more N1 nodes injecting it transpleurally and then we found slightly more N2 nodes in the second trial, potentially related to a longer time from injection to visualization.

Dr Egan. No. What I meant, if it was an N1 node, was it at the hilum of the lobe? And the other question is, did you find any pickup in the visceral pleura or is it just too diffuse?

Dr Digesu. As far as I know, there were no sentinel nodes in the visceral pleura.

Dr Egan. Not nodes, just pickup, because the pattern of lymphatic drainage is out to the visceral pleura and then around to the hilum, which is the rationale for doing a lobectomy in the first place rather than a segmentectomy. So I was just curious whether your pickup is sensitive enough to see your dye or your marker in the visceral pleura or does it have to be in a node?

Dr Digesu. As far as I have seen, the ones we have been able to identify the node itself, there is some spread, as you are saying, along the visceral pleura. That signal is usually not very bright, so it is easy to pick up the node itself, because the ICG pools within the node.

Dr Egan. And how often was there more than one node?

Dr Digesu. Only in about 5 of the patients we had 2 nodes, but never more than 2 .

Dr Egan. Thank you.

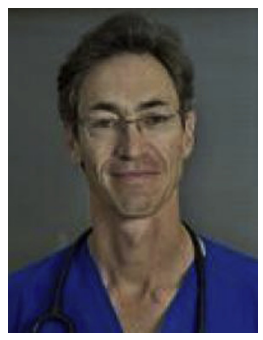

Dr Joseph B. Shrager (Stanford, Calif). Yolonda might want to address this when she speaks also. We have to be careful when we talk about survival results. This was obviously not powered to be a survival study and this may be random chance in terms of the survival.

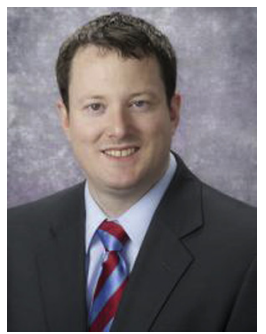

Dr David D. Odell (Chicago, Ill). I have a pretty simple question. In the group where you compared the clinically No patients that were sentinel node positive against those who were sentinel node negative, one thing that I didn't see in the data that you presented is the extent of lymphadenectomy that was done in standard of care. Do you have any data about the number of nodes or perhaps more importantly the stations that were sampled in the patients in those 2 groups?

Dr Digesu. We did a comparison between the number of nodes as well as the number of stations that were sampled, and there was no difference.

Dr Shrager. Yolonda?

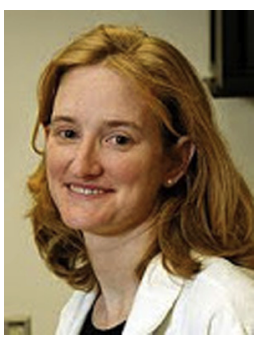

Dr Yolonda L. Colson (Boston, Mass). A couple of things. One is that we realized that this doesn't have a big sample size. To me, it was important that if we were going to talk about doing sentinel lymph nodes, it is not exactly the same as breast where we say there is a morbidity difference. One of the reasons to try to look at this was to see, is there an advantage to us to do this over a lymphadenectomy or a sentinel lymph node. And when we actually compared the groups as we were going through, because in the first group we didn't have enough to actually get enough dye to see it, and the second was, as we got to start to get them, did it make a difference, did we learn anymore information? So we actually have 3 to 4 stations in each group sampled, and there is a previous publication of both the navigational bronchoscopy and the transpleural which actually goes through and 
analyzes both of these groups in terms of the actual lymph node dissections that were done.

The reason that we have so many wedges in the group was because that was particularly the group we wanted to know, could we add anything. Because we thought they would be the ones who would have the highest risk of recurrence and locoregional recurrence, we purposely chose those to say these would be the people that I think would really benefit from more information, and that's why there is that percentage in the group. I understand the issues of trying to wedge and maybe not doing that, but our thought was that would be the group that we would hopefully benefit more than the ones that had the whole lobectomy and the full lymphadenectomy was to try to figure out that group, particularly the ones that have something that is small and nonpalpable, and right now people wedge out and never really go into the nodes, and I think it is making sure we can do that.

The reason about depending on the depth of how deep you go, if you are really shallow, you can get the whole visceral pleura and you can see it come around. It is harder then to figure out where the node is, though. So one of the reasons of trying to work out the technique is if we find that balance where if we are deep enough we don't get the leak and we don't get all the visceral pleura, we actually can start to identify a single site. Interestingly enough, at least you can find one or two, we haven't had a bunch of them, and we have been able to do something.
We recognize the numbers aren't big, we recognize we don't have the answer, which is why we are talking about trying to do a multicenter study, because it doesn't matter if we can get it to work in our lab, it only matters if it works in everyone else's and everyone else's OR, and I think what we are just trying to do is to figure out how we could use it before we all invest time trying to do it.

That's my comment.

Dr Shrager. Dr Yasufuku, you have a final question?

Dr Yasufuku. A final question. Yolonda, what about the challenges of identifying the lobar and the segmental lymph nodes, because if you are going to do a wedge, how do we look for a station 12 or a station 13 ? Is there technology that you are considering? I know ICG drains quickly and by the time you are finished with the dissection it may be gone. So is there anything that you are up to?

Dr Colson. One of the things is the liposomal ICG concept, some of these other ways of mixing it so it slows down as it is going is one advantage. The other interesting thing, though, is we haven't seen a recurrence, so we are up to the N1's and is that close enough? I don't know that. We have tried to dissect up. On some cases we actually get a green line and so you can see where it goes and then you can open up your sublobars to do that. We just haven't quite got where we can see all the time the line where it is, and I think it is mixing it with things that make it slower. 